\begin{tabular}{|c|c|}
\hline Title & Suppression of Field Crystallization of A nodic Niobia by Oxygen \\
\hline Author(s) & $\begin{array}{l}\text { Habazaki, H.; Ogasawara, T.; Konno, H.; Shimizu, K.; Nagata, S.; A sami, K.; Takay ama, K.; Skeldon, P.; Thompson, } \\
\text { G. E. }\end{array}$ \\
\hline Citation & $\begin{array}{l}\text { Journal of the Electrochemical Society, 153(5), B173-B177 } \\
\text { https://doi.org/10.1149/.2184909 }\end{array}$ \\
\hline Issue Date & $2006-03-27$ \\
\hline Doc URL & http://hdl.handle.net/2115/8430 \\
\hline Rights & Copyright $\odot 2006$ The Electrochemical Society \\
\hline Type & article \\
\hline File Information & JES_153(5)_B173-B177.pdf \\
\hline
\end{tabular}

Instructions for use 


\title{
Suppression of Field Crystallization of Anodic Niobia by Oxygen
}

\author{
H. Habazaki, ${ }^{a, *, z}$ T. Ogasawara, ${ }^{a}$ H. Konno, ${ }^{a, *}$ K. Shimizu, ${ }^{b}$ S. Nagata, ${ }^{c}$ \\ K. Asami, ${ }^{\mathrm{c}}$ K. Takayama, ${ }^{\mathrm{d}}$ P. Skeldon, ${ }^{\mathrm{e}, *}$ and G. E. Thompson ${ }^{\mathrm{e}, * *}$ \\ ${ }^{a}$ Graduate School of Engineering, Hokkaido University, Sapporo 060-8628, Japan \\ ${ }^{b}$ University Chemical Laboratory, Keio University, Yokohama 223-8521, Japan \\ ${ }^{c}$ Institute for Materials Research, Tohoku University, Sendai 980-8577, Japan \\ ${ }^{d}$ Cabot Supermetals Company, Limited, Kawahigashi-machi, Kawanuma-gun, Fukushima, 969-3431, Japan \\ ${ }^{e}$ Corrosion and Protection Centre, School of Materials, The University of Manchester, Manchester \\ M60 1OD, United Kingdom
}

Solid-solution $\mathrm{Nb}-\mathrm{O}$ films containing up to 50 atom $\%$ oxygen, prepared by magnetron sputtering, were used to investigate the influence of the oxygen on field crystallization during anodizing at $100 \mathrm{~V}$ in $0.1 \mathrm{~mol} \mathrm{dm}^{-3}$ ammonium pentaborate electrolyte at $333 \mathrm{~K}$. The findings reveal that field crystallization is hindered dramatically by addition of 20 atom $\%$ oxygen to the substrate, while no crystallization occurs for a $\mathrm{Nb}-50$ atom \% O substrate. Prior thermal treatment accelerates field crystallization of niobium, but not the $\mathrm{Nb}-50$ atom $\% \mathrm{O}$ substrate. The thermal treatment is considered to promote generation of precursor sites for crystal nucleation. However, sufficient oxygen in the substrate may restrict precursor development and/or reduce the compressive stresses in the amorphous anodic niobia that can facilitate crystal growth.

(C) 2006 The Electrochemical Society. [DOI: 10.1149/1.2184909] All rights reserved.

Manuscript submitted October 28, 2005; revised manuscript received January 10, 2006. Available electronically March 27,2006

Niobium is a potential alternative material to tantalum for electrolytic capacitors due to its many attractive properties ${ }^{1}$ and its relatively high natural abundance. However, niobium capacitors are more susceptible to field crystallization during both growth of the anodic oxide dielectric and packaging of capacitors. Field crystallization in niobium and tantalum leads to degradation of the initial amorphous oxide, involving cracking and peeling due to growth of crystalline oxide, ${ }^{2}$ which increases the leakage current. The effects are enhanced at increased anodizing temperatures and forming voltages. $^{2-4}$ Inclusions ${ }^{5,6}$ and roughness, especially convex surfaces, of the substrate assist crystal nucleation. ${ }^{7,8}$ Recent studies using flat, inclusion-free, magnetron-sputtered niobium suggested nucleation is associated with precursor sites in the original, air-formed film, while incorporation of foreign species from the electrolyte or from the substrate at precursor regions can hinder nucleation. ${ }^{9}$ Other investigations indicate an enhanced susceptibility to field crystallization due to oxygen impurity in the substrate. ${ }^{5,10,6,11}$ Oxide precipitates, possibly at grain boundaries, may be involved, although the detailed processes are not well understood. Here, the influence of oxygen in the substrate is examined on field crystallization of the anodic niobia.

\section{Experimental}

Niobium and $\mathrm{Nb}-(20$ and 50$)$ atom $\%$ O films were deposited by sputtering $99.9 \%$ niobium in either argon or a mixture of argon and oxygen at $\sim 0.1 \mathrm{~Pa}$ using magnetron sputtering enhanced with a radio frequency plasma source to increase the plasma density. Three types of flat substrate were employed: glass plates, silicon wafers, and electropolished and anodized aluminum sheets. Subsequent thermal treatment of the deposited films, either in air at 523-623 K for $1.8 \mathrm{ks}$ or in vacuum $\left(\sim 10^{-5} \mathrm{~Pa}\right)$ at $923 \mathrm{~K}$, was employed selectively. Structures of the deposits were determined by X-ray diffraction (XRD) (Rigaku RINT 2000) using $\mathrm{Cu} \mathrm{K} \alpha$ radiation, with patterns obtained in an $\alpha-2 \theta\left(\alpha=1^{\circ}\right)$ mode.

The films were anodized at $50 \mathrm{~A} \mathrm{~m}^{-2}$ to $100 \mathrm{~V}$ with current decay in stirred $0.1 \mathrm{~mol} \mathrm{dm}^{-3}$ ammonium pentaborate electrolyte at $333 \mathrm{~K}$. A platinum sheet was used as a counter electrode. Surfaces of the anodized specimens were observed using field emission gun scanning electron microscopy (JEOL JSM-6300F). Ultramicrotomed

\footnotetext{
* Electrochemical Society Active Member.

** Electrochemical Society Fellow.

${ }^{\mathrm{z}}$ E-mail: habazaki@eng.hokudai.ac.jp
}

sections, about $10 \mathrm{~nm}$ thick, of anodic films, were observed using a JEOL JEM-2010 transmission electron microscope operating at $200 \mathrm{kV}$.

As reported previously, the niobium and $\mathrm{Nb}-20$ atom $\%$ O films have a body-centered cubic (bcc) structure, with the latter having a reduced grain size. ${ }^{12}$ The XRD pattern of the $\mathrm{Nb}-50$ atom $\% \mathrm{O}$ films reveals only the broad peak of an amorphous structure, while following vacuum annealing films are transformed to crystalline $\mathrm{NbO}$ with a NaCl-type cubic structure (Fig. 1).

Typical current-time curves for the as-deposited niobium, $\mathrm{Nb}-20$ atom $\% \mathrm{O}$ and $\mathrm{Nb}-50$ atom $\% \mathrm{O}$ films during anodizing are revealed in Fig. 2. The specimens were initially subjected to a galvanostatic condition of $50 \mathrm{~A} \mathrm{~m}^{-2}$, then, after reaching $100 \mathrm{~V}$, to a constant voltage condition. After reaching $100 \mathrm{~V}$, the current decreases rapidly with a minimum at $\sim 1.0 \mathrm{ks}$ for the oxygen-free niobium, followed by current increase due to field crystallization. The latter is delayed for the $\mathrm{Nb}-20$ atom $\% \mathrm{O}$, and is absent for the $\mathrm{Nb}-50$ atom $\%$ O film.

Scanning electron microscopy (SEM) reveals a flat, featureless surface typical of amorphous niobia following the galvanostatic pe-

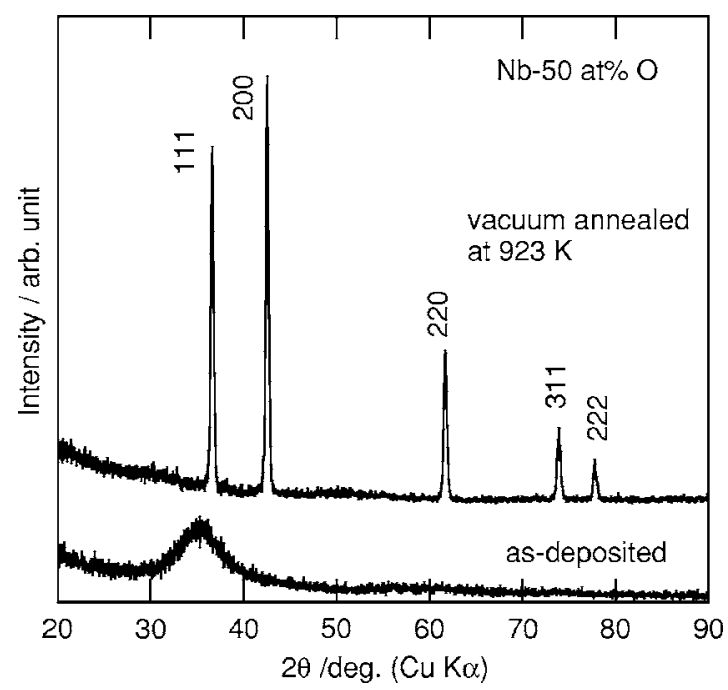

Figure 1. $\mathrm{XRD}$ patterns of the $\mathrm{Nb}-50$ atom $\% \mathrm{O}$ films in the as-deposited condition and following annealing in vacuum at $923 \mathrm{~K}$. 


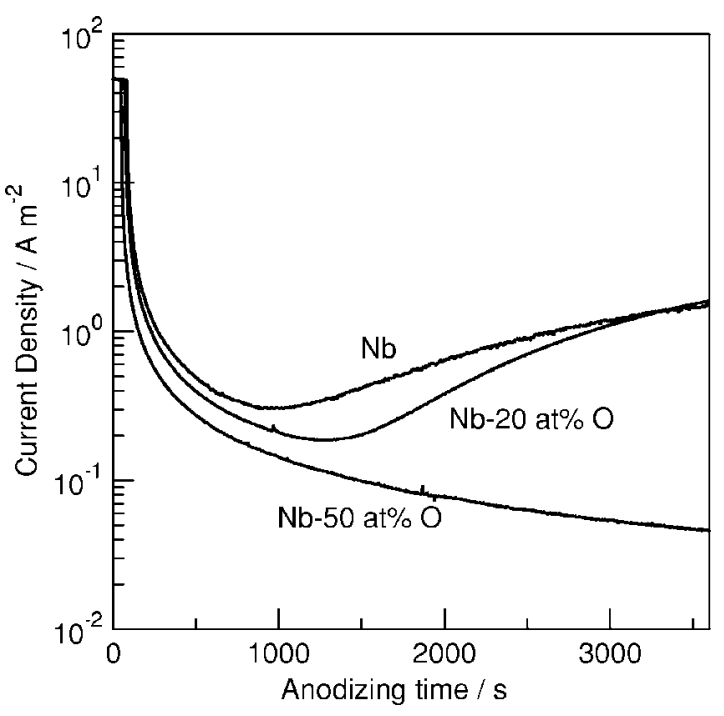

Figure 2. Current-time curves of the as-deposited niobium, $\mathrm{Nb}-20$ atom $\%$ $\mathrm{O}$ and $\mathrm{Nb}-50$ atom $\% \mathrm{O}$ films during anodizing for $3.6 \mathrm{ks}$ in $0.1 \mathrm{~mol} \mathrm{dm}^{-3}$ ammonium pentaborate electrolyte at $333 \mathrm{~K}$. Initially, a constant current density of $50 \mathrm{~A} \mathrm{~m}^{-2}$ was applied until the formation voltage of $100 \mathrm{~V}$ was reached. Then the voltage of $100 \mathrm{~V}$ was maintained.

riod of anodizing niobium (Fig. 3a). In contrast, crystalline regions are present when the current has decayed to the minimum value (Fig. 3b). These regions subsequently enlarge, with peeled oxide located around the crystalline regions (Fig. 3c), typical of the morphology of field crystallization in anodic niobia and tantala., $23,3,4$ For the $\mathrm{Nb}-20$ atom $\% \mathrm{O}$ film, no crystals are resolved after anodizing for $1.0 \mathrm{ks}$, while the extent of crystalline regions is reduced relative to oxygen-free niobium at $3.6 \mathrm{ks}$ (Fig. 4). Further, crystals are absent on both the amorphous and crystalline $\mathrm{Nb}-50$ atom $\% \mathrm{O}$ substrate after the latter time (Fig. 5), confirming the inhibition of crystallization by oxygen within the niobium substrate.

Regions of uniform amorphous oxide, $354 \mathrm{~nm}$ thick, and others of crystalline oxide, about $100 \mathrm{~nm}$ thick, were revealed by transmission electron microscopy (TEM) in the anodic film formed for $3.6 \mathrm{~s}$ on the niobium substrate (Fig. 6). Detachment of outer oxide, either during film growth or sectioning, accounts for the low thickness of the latter regions. The absence of niobium metal only beneath the crystalline oxide indicates a comparatively fast oxide growth.

As evident from Fig. 7, thermal treatment in air accelerates field crystallization of niobium, with the current increasing at shorter time with increasing treatment temperature, suggesting more ready nucleation of crystalline oxide (Fig. 8). In contrast, thermal pretreatment did not induce field crystallization of the resistant $\mathrm{Nb}-50$ atom $\% \mathrm{O}$ films, which was also evident from TEM (Fig. 9) and additionally confirmed by SEM.

\section{Discussion}

Recent results of the authors on field crystallization on sputterdeposited niobium ${ }^{9}$ suggested that crystal nucleation originates from precursors in the prior air-formed oxide on the deposited metal. Thermal treatment of the substrate in air at $523 \mathrm{~K}$ enhanced nucleation, while vacuum treatment of the air-formed oxide at the same temperature had an opposite effect. The crystal growth develops from about $25 \%$ of the anodic film thickness, which marks the original location of precursors. Further, incorporation of phosphorus species from electrolyte, as well as tungsten and nitrogen species from the substrate, into the region of precursor sites inhibits crystallization. The behavior contrasts with anodic titania, in which crystal
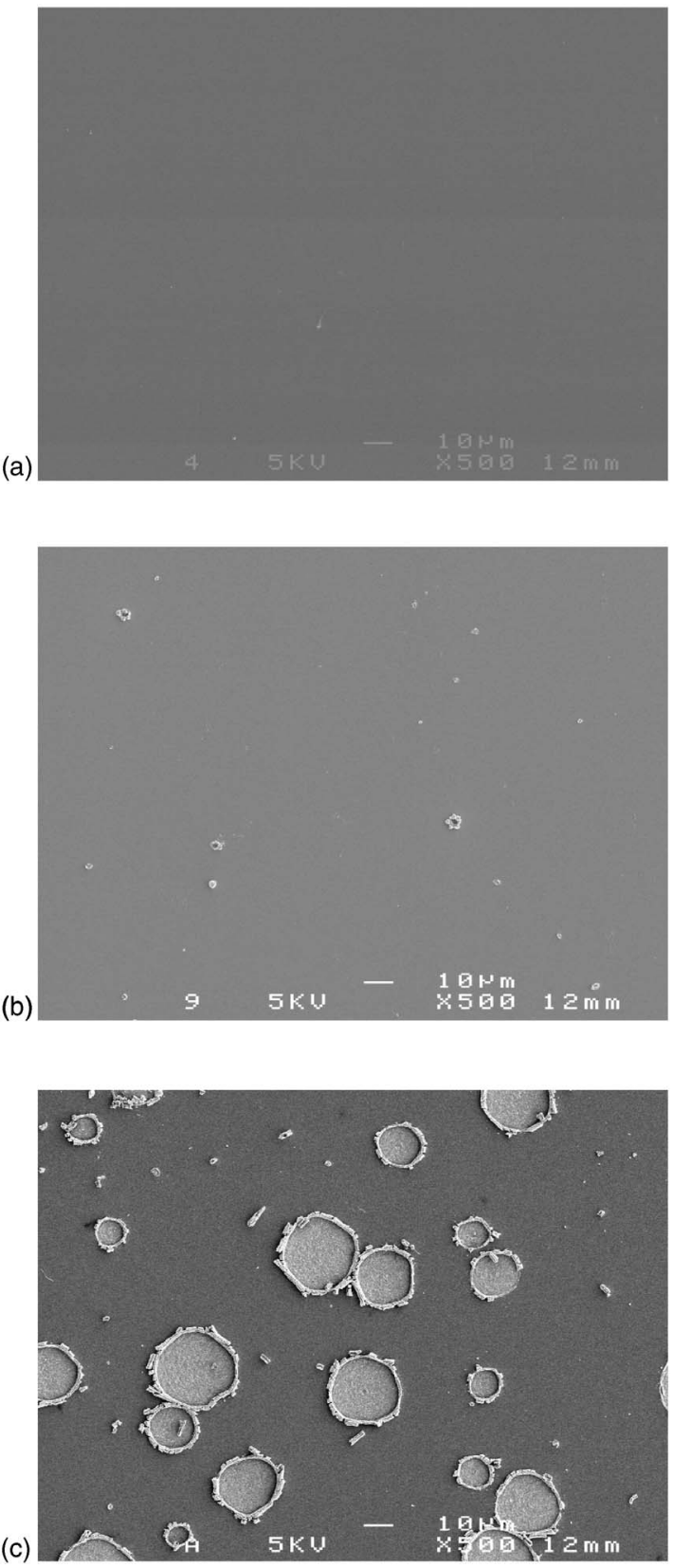

Figure 3. SEMs of the surfaces of the niobium films after anodizing at $100 \mathrm{~V}$ in $0.1 \mathrm{~mol} \mathrm{dm}^{-3}$ ammonium pentaborate electrolyte at $333 \mathrm{~K}$ : (a) just reaching $100 \mathrm{~V}$, (b) anodizing for $1.0 \mathrm{ks}$, and (c) for $3.6 \mathrm{ks}$.

formation is associated mainly with sites at the metal/film interface. ${ }^{14}$ The present results confirm the importance of the surface condition of the niobium, showing enhanced nucleation of crystalline oxide by increasing temperature of thermal treatment. The accelerated crystallization with increased temperature, evident during holding at a constant formation voltage, suggests that the precursors of crystalline oxide, possibly regions of short-range to mediumrange order, are developed in the thermal oxide. The precursors had negligible influence in the initial period of galvanostatic anodizing when a mainly amorphous oxide forms, with the time to reach $100 \mathrm{~V}$ being independent of the thermal treatment temperature. The amorphous niobia formed in this stage is developed by simultaneous countermigrations of $\mathrm{Nb}^{5+}$ ions outward and $\mathrm{O}^{2-}$ ions inward, ${ }^{15}$ with a transport number of cations of about $0.25,{ }^{16}$ with the precise value depending upon the field strength and hence, current density and temperature. ${ }^{7,18}$ For the present anodizing conditions, the precur- 
(a)

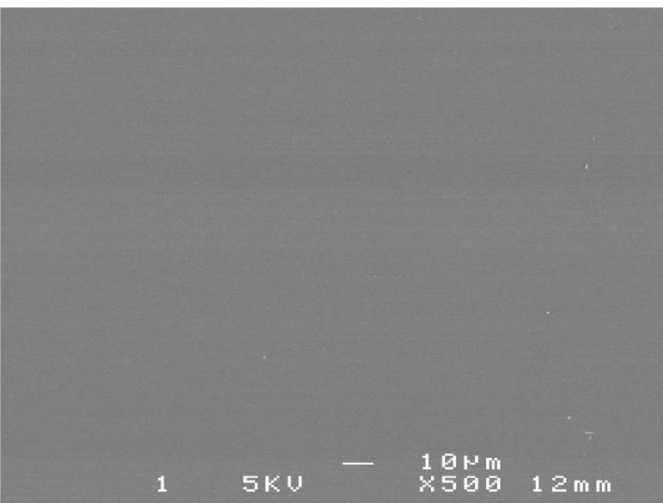

(b)

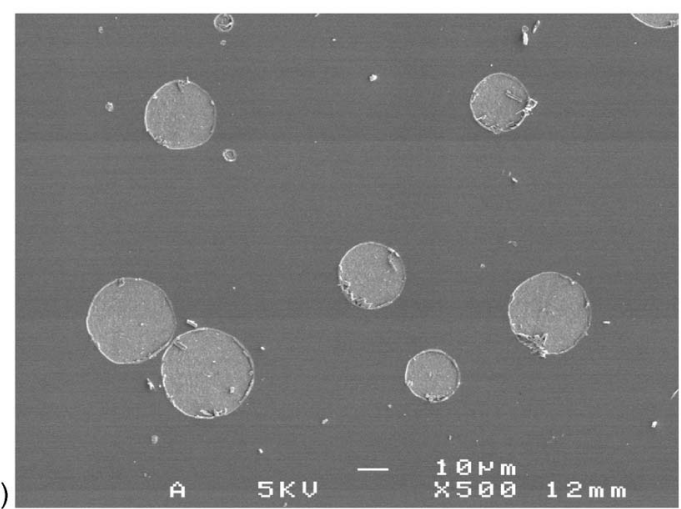

Figure 4. SEMs of the surfaces of the $\mathrm{Nb}-20$ atom $\% \mathrm{O}$ films after anodizing at $100 \mathrm{~V}$ in $0.1 \mathrm{~mol} \mathrm{dm}^{-3}$ ammonium pentaborate electrolyte at $333 \mathrm{~K}$ for (a) $1.0 \mathrm{ks}$ and (b) $3.6 \mathrm{ks}$.

sors or developing fine crystal nuclei, presumed to be essentially immobile in the surrounding amorphous oxide, are located at a depth of $\sim 25 \%$ of the anodic film thickness during the stage of galvanostatic anodizing. From these sites, relatively large crystals develop during the subsequent potentiostatic stage of anodizing.

Addition of 20 atom \% oxygen to niobium retards crystallization and the associated current increase, with increased levels to 50 atom $\%$ also resisting the accelerating effects of thermal treatment found with oxygen-free niobium. The beneficial role of oxygen may particularly relate to its influence on oxide stresses and their influence on development of crystals from precursors. Leach and Pearson have reported that high compressive stresses are conducive to crystal formation in anodic oxides. ${ }^{19}$ Such stresses can arise from the volume change associated with growth of oxide at the metal/film interface. In the $\mathrm{Nb}-\mathrm{O}$ system, the Pilling-Bedworth ratio (PBR) and the ratio of anodic oxide thicknesses formed at the metal/film and film/electrolyte interfaces depend upon the substrate composition. Although for the data in Table $\mathrm{I}^{12}$ the anodizing conditions differ from those of the present study, the results should be reasonably applicable here. In particular, the large decrease in PBR, although offset partly by increased growth at the metal/film interface,

Table I. The Pilling-Bedworth ratio (PBR) and the growth ratio of the oxide at the metal/film interface during the growth of anodic niobia at $50 \mathrm{~A} \mathrm{~m}^{-2}$ to $100 \mathrm{~V}$ without current decay in $0.1 \mathrm{~mol} \mathrm{dm}^{-3}$ phosphoric acid electrolyte at $293 \mathrm{~K}$.

\begin{tabular}{ccc} 
Substrate & PBR & Growth ratio \\
\hline $\mathrm{Nb}$ & 2.5 & 0.70 \\
$\mathrm{Nb}-20$ atom $\% \mathrm{O}$ & 2.0 & 0.74 \\
$\mathrm{Nb}-50$ atom $\% \mathrm{O}$ & 1.6 & 0.83
\end{tabular}

(a)

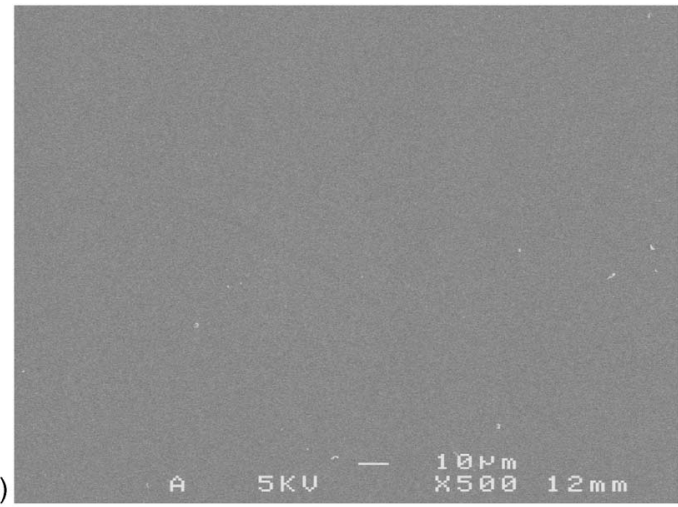

(b)

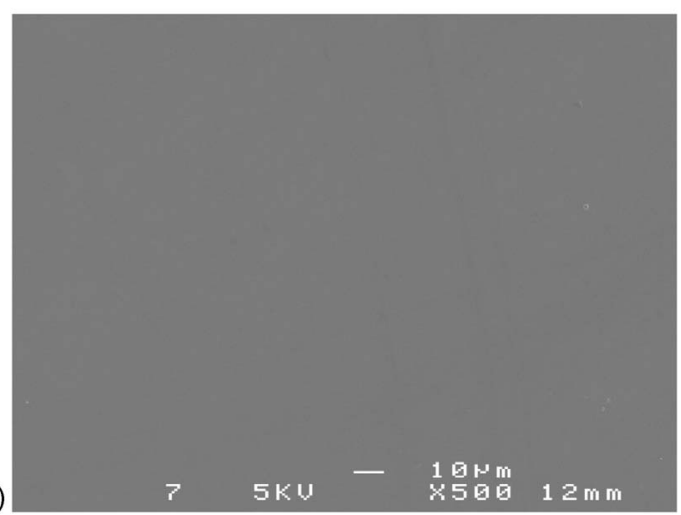

Figure 5. SEMs of the surfaces of the (a) amorphous and (b) crystalline $\mathrm{Nb}-50$ atom $\% \mathrm{O}$ films after anodizing at $100 \mathrm{~V}$ in $0.1 \mathrm{~mol} \mathrm{dm}^{-3}$ ammonium pentaborate electrolyte at $333 \mathrm{~K}$ for $3.6 \mathrm{ks}$. The crystalline $\mathrm{Nb}-50$ atom \% O film was obtained by vacuum annealing of the as-deposited amorphous film.

with increasing oxygen content should reduce compressive stresses that promote crystallization. Further, a reduced PBR may also restrict the otherwise fast growth of the crystalline oxide that is evident in Fig. 6 by limiting oxide cracking. Other growth properties of the anodic oxides, including the transport number of cations and field strength as well as anodic film properties such as permittivity and density of anodic oxide, are almost independent of the oxygen content in niobium, ${ }^{12}$ suggesting negligible influences in the altered field crystallization behavior.

The role of the crystal structure of the substrate requires further attention. Field crystallization occurs here for the bcc niobium and $\mathrm{Nb}-20$ atom $\% \mathrm{O}$ films, with the latter having a finer grain size of approximately $4 \mathrm{~nm}$, whereas it is absent for the $\mathrm{Nb}-50$ atom \% O film in either amorphous or $\mathrm{NaCl}$-type $\mathrm{NbO}$ structures. In contrast to anodizing, crystalline oxide develops readily on the crystalline $\mathrm{NbO}$ substrate, but not the amorphous substrate, during thermal oxidation in air at $723 \mathrm{~K}$ (Fig. 10).

\section{Conclusions}

Field crystallization of anodic niobia on crystalline sputterdeposited niobium substrates during anodizing at $100 \mathrm{~V}$ in $0.1 \mathrm{~mol} \mathrm{dm}^{-3}$ ammonium pentaborate electrolyte at $333 \mathrm{~K}$ is retarded by addition of 20 atom $\%$ oxygen. Further, field crystallization was absent on both the amorphous and $\mathrm{NaCl}$-type $\mathrm{Nb}-50$ atom $\% \mathrm{O}$ substrates. Prethermal treatment accelerates the nucleation of crystalline oxide for niobium substrates, suggesting that the thermal oxide provides percursor sites for crystal growth. Reduced compressive stress upon addition of oxygen, associated with changes in 
(a)
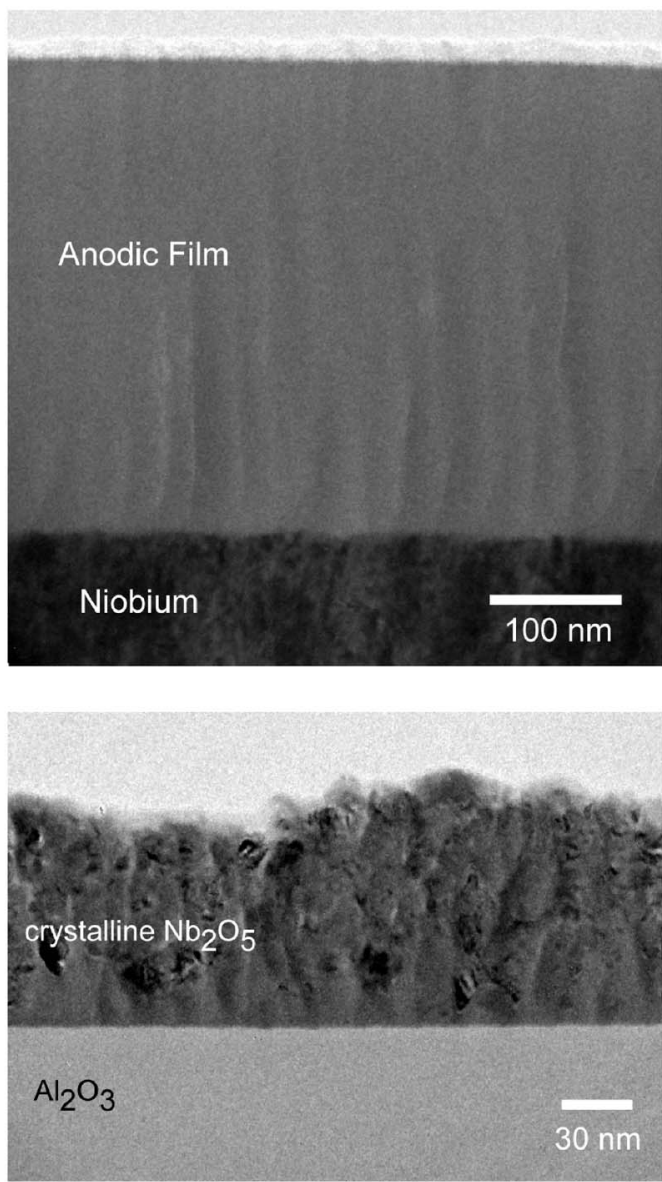

Figure 6. TEMs of ultramicrotomed sections of (a) amorphous and (b) crystalline regions of the anodic films formed on the niobium film at $100 \mathrm{~V}$ in $0.1 \mathrm{~mol} \mathrm{dm}^{-3}$ ammonium pentaborate electrolyte at $333 \mathrm{~K}$ for $3.6 \mathrm{ks}$.

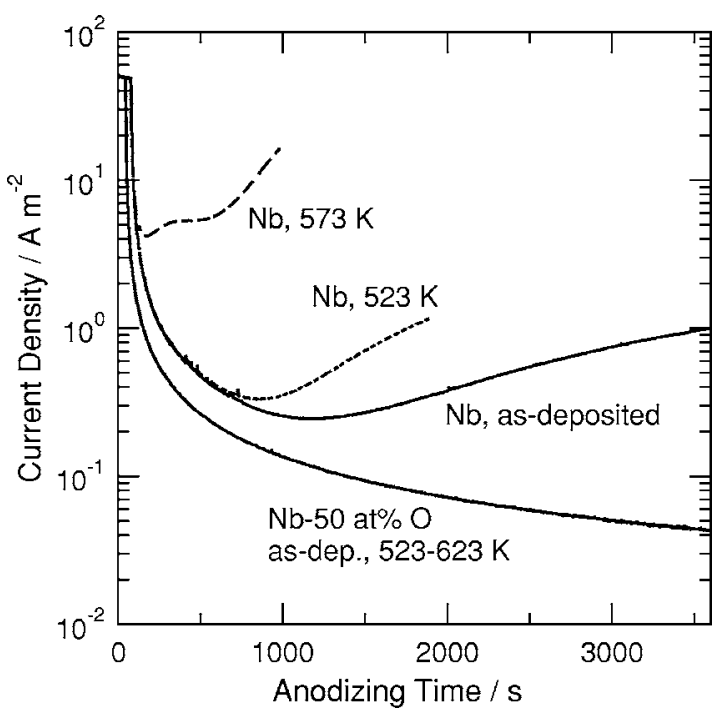

Figure 7. Current-time curves of the niobium films, both as-deposited and thermally treated at 523 and $573 \mathrm{~K}$, as well as the $\mathrm{Nb}-50$ atom \% O films, both as-deposited and thermally treated at $523-623 \mathrm{~K}$, during anodizing at $100 \mathrm{~V}$ in $0.1 \mathrm{~mol} \mathrm{dm}^{-3}$ ammonium pentaborate electrolyte at $333 \mathrm{~K}$.
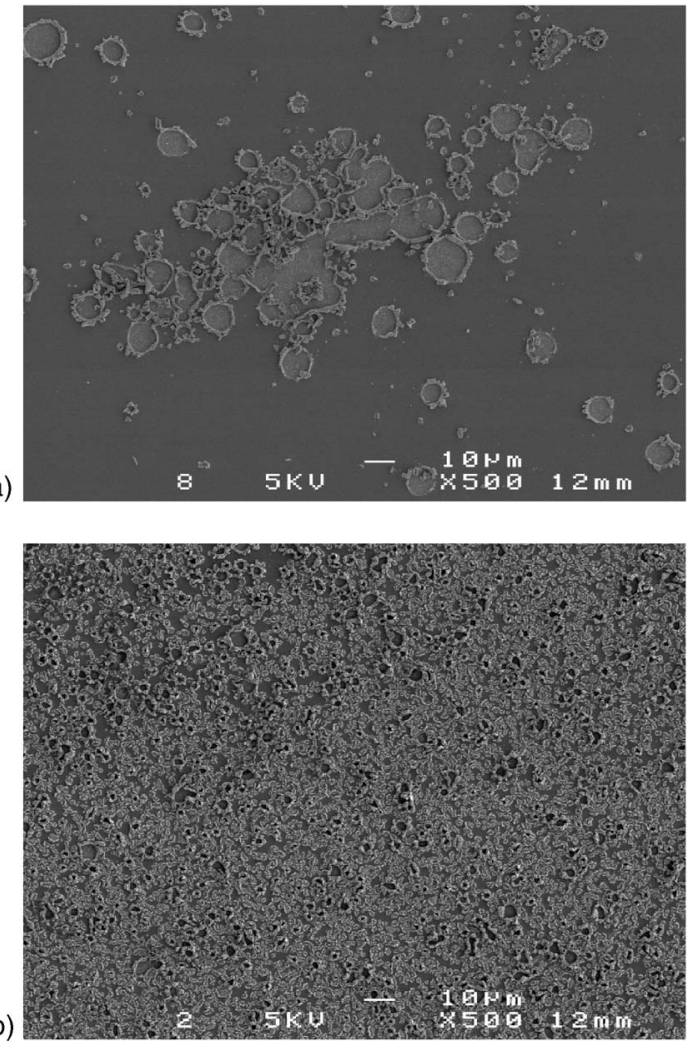

Figure 8. SEMs of the surfaces of the niobium films thermally treated at (a) 523 and (b) $573 \mathrm{~K}$ and subsequently anodized at $100 \mathrm{~V}$ in $0.1 \mathrm{~mol} \mathrm{dm}^{-3}$ ammonium pentaborate electrolyte at $333 \mathrm{~K}$ for $3.6 \mathrm{ks}$.

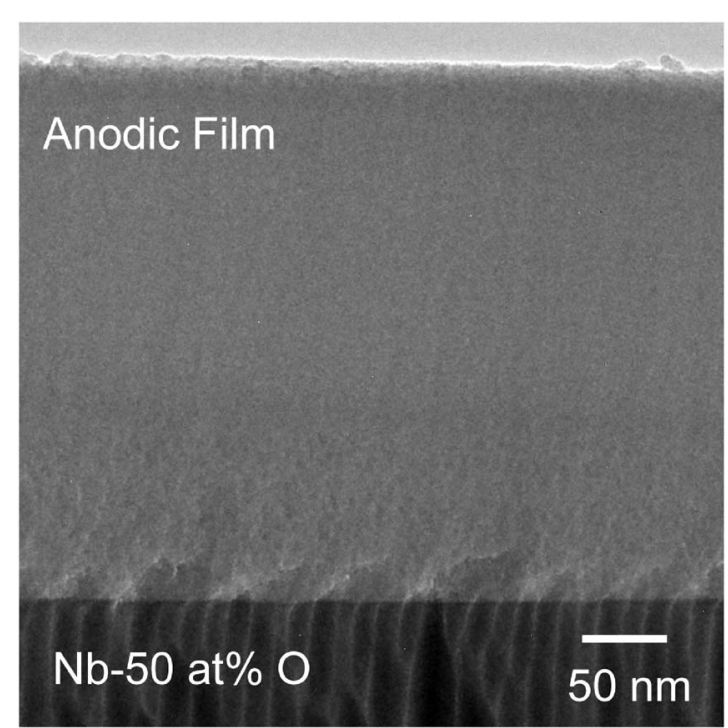

Figure 9. TEM of an ultramicrotomed section of the $\mathrm{Nb}-50$ atom $\%$ film thermally treated at $523 \mathrm{~K}$ and subsequently anodized at $100 \mathrm{~V}$ in $0.1 \mathrm{~mol} \mathrm{dm}^{-3}$ ammonium pentaborate electrolyte at $333 \mathrm{~K}$ for $3.6 \mathrm{ks}$. 


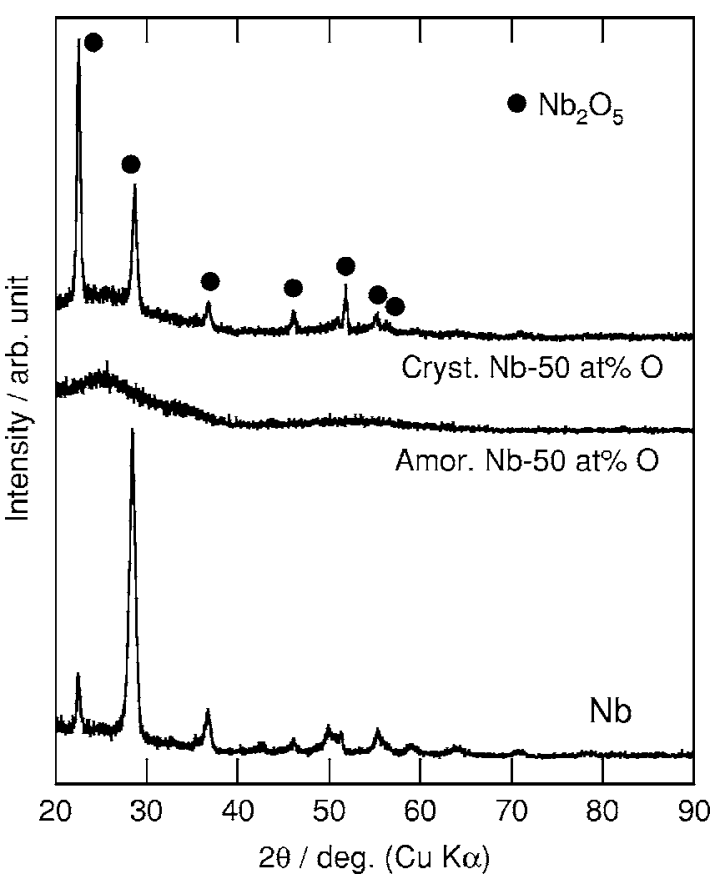

Figure 10. XRD patterns of the niobium film and the amorphous and crystalline $\mathrm{Nb}-50$ atom $\% \mathrm{O}$ films after oxidation in air at $723 \mathrm{~K}$ for $3.6 \mathrm{ks}$. The crystalline $\mathrm{Nb}-50$ atom $\% \mathrm{O}$ film was obtained by vacuum annealing of the as-deposited amorphous film.

PBRs and the thickness ratios of oxide formed at the metal/film and film/electrolyte interfaces, probably hinder field crystallization, with sufficient oxygen overriding the potentially adverse influences of thermal treatment.

\section{Acknowledgments}

Thanks are due to K. Saito of the Institute for Materials Research, Tohoku University, for the preparation of niobium and $\mathrm{Nb}-\mathrm{O}$ films. The present work was supported in part by a Grant-in-Aid for Scientific Research, no. 16360353, from the Japan Society for the Promotion of Science.

Hokkaido University assisted in meeting the publication costs of this article.

\section{References}

1. C. V. D'Alkaine, L. M. M. Desouza, and F. C. Nart, Corros. Sci., 34, 109 (1993). 2. D. A. Vermilyea, J. Electrochem. Soc., 102, 207 (1955).

3. N. F. Jackson, J. Appl. Electrochem., 3, 91 (1973).

4. N. F. Jackson and J. C. Hendy, Electrocomponent Sci. Tech., 1, 27 (1974).

5. D. A. Vermilyea, J. Electrochem. Soc., 104, 542 (1957).

6. Y. Pozdeev-Freeman, Y. Rozenberg, A. Gladkikh, M. Karpovski, and A. Palevski, J. Mater. Sci.: Mater. Electron., 9, 309 (1998).

7. K. Nagahara, M. Sakairi, H. Takahashi, K. Matsumoto, K. Takayama, and Y. Oda, Electrochemistry (Tokyo, Jpn.), 72, 624 (2004).

8. K. Nagahara, M. Sakairi, H. Takahashi, S. Nagata, K. Matsumoto, K. Takayama, and Y. Oda, J. Surf. Finish. Soc. Jpn., 55, 943 (2004).

9. H. Habazaki, T. Ogasawara, H. Konno, K. Shimizu, S. Nagata, K. Takayama, P. Skeldon, and G. E. Thompson, Corros. Sci., Submitted.

10. Y. Pozdeev-Freeman, A. Gladkikh, M. Karpovski, and A. Palevski, J. Electron. Mater, 27, 1034 (1998)

11. Y. Pozdeev-Freeman and A. Gladkikh, J. Electron. Mater, 30, 931 (2001).

12. H. Habazaki, T. Ogasawara, H. Konno, K. Shimizu, K. Asami, K. Saito, S. Nagata, P. Skeldon, and G. E. Thompson, Electrochim. Acta, 50, 5334 (2005).

13. D. M. Lakhiani and L. L. Shreir, Nature (London), 188, 49 (1960).

14. H. Habazaki, M. Uozumi, H. Konno, K. Shimizu, P. Skeldon, and G. E. Thompson, Corros. Sci., 45, 2063 (2003).

15. L. Young and D. J. Smith, J. Electrochem. Soc., 126, 765 (1979).

16. J. P. S. Pringle, Electrochim. Acta, 25, 1420 (1980).

17. Q. Lu, P. Skeldon, G. E. Thompson, D. Masheder, H. Habazaki, and K. Shimizu, Corros. Sci., 46, 2817 (2004).

18. S. Ono, M. Baba, M. Shimoyama, and H. Asoh, in Surface Oxide Films, V. Birss, L. Burke, A. R. Hillman, and R. S. Lillard, Editors, PV 2003-25, p. 133, The Electrochemical Society Proceedings Series, Pennington, NJ (2003).

19. J. S. L. Leach and B. R. Pearson, Corros. Sci., 28, 43 (1988). 